\title{
Understanding Teacher Well-Being During the Covid-19 Pandemic Over Time: A Qualitative Longitudinal Study
}

\author{
Heather L. Walter \\ The George Washington University \\ Hallie B. Fox \\ The George Washington University
}

Teacher stress and burnout under non-crisis situations are well-documented challenges. However, during COVID-19, teachers have faced new and unexpected stressors, potentially contributing to rising burnout and attrition. Yet many teachers have also demonstrated great resilience and found effective ways to manage their well-being. To explore teacher well-being during COVID-19, this study used a longitudinal qualitative design that employed recurrent cross-sectional analysis using wo conceptual frameworks including the job-demands-resource model of well-being and the hierarchy of needs theory of motivation. Researchers investigated 25 teacher's well-being during COVID-19 at two time points (June 2020 and March 2021). Both barriers and facilitators of well-being at the individual and contextual levels are discussed.

Keywords: teacher well-being during COVID-19, longitudinal qualitative analysis, teacher resiliency, teacher retention

\section{INTRODUCTION}

Teaching can be an incredibly rewarding and fulfilling profession but is also frequently cited as one of the most stressful (Billingsley et al 2019; Wong, 2017). Unfortunately, teacher stress and burnout are not only associated with high attrition rates but also poor academic and social-emotional outcomes for students (Jennings et al, 2017; UNHC, n.d). Even under non-crisis teaching situations, teacher turnover and attrition is a major challenge facing many schools in the Western world and particularly in the U.S. During COVID19, many of the stressors associated with the job have been amplified, particularly for individuals simultaneously supporting family at home and teaching in remote or hybrid formats. In the United States, stress during COVID-19 has driven many teachers out of the classroom (Diliberti, et al., 2021).

However, high stress, burnout, and attrition have not characterized all teachers' experiences during the pandemic. Some teachers have maintained job satisfaction, particularly when they feel highly supported, have clear roles and responsibilities, and have ample opportunities for training (Kraft et al., 2020). Understanding what factors promote teacher well-being and reduce stress, particularly under prolonged emergency situations such as COVID-19, can help school and district leaders better support teachers and reduce rates of turnover in the short and long-term. 


\section{LITERATURE REVIEW}

\section{Teacher Well-Being}

Teacher well-being is often described by its opposite - stress and burnout. Thus, much of the research on well-being has, instead, focused on indicators of stress such as isolation, challenging student behavior, inadequate administrative support, or low salaries, but this research has not yet led to improved teacher well-being and retention (Brunsting et al., 2014; Player et al., 2017). This deficit-based focus includes an extensive body of research related to factors that cause teachers to leave the classroom but substantially less related to positive indicators of teacher retention and well-being (e.g. Carver-Thomas \& Darling-Hammond, 2016; Skaalvik \& Skaalvik, 2011). More recently, there has been growing interest in identifying what facilitates teacher well-being and retention (McCallum et al., 2017). When teachers are well, they are more likely to stay in the profession and have higher levels of life and work satisfaction (Kern et al., 2014). This includes having a high sense of meaning and accomplishment but also positive relationships and engagement with colleagues (Kern et al., 2014).

Although there is a general lack of clarity about the meaning of "teacher well-being," most agree it is a multidimensional construct related to satisfaction and fulfillment at work (Acton \& Glasgow, 2015; Bricheno et al., 2009; McCallum et al., 2017). It can be thought of as a positive emotional state, which is the result of harmony between environmental factors and individual needs (Aelterman et al., 2007). This definition, among others emphasizes a psychosocial perspective in which teachers well-being involves interaction between the individual and the broader school environment.

\section{Factors That Impact Teacher Well-Being}

While a majority of research in this area has focused on negative indicators of teacher well-being, such as student misbehavior or low pay, there is growing interest in factors that positively facilitate teacher wellbeing (McCallum et al., 2017). This includes positive facilitators at the individual, interpersonal, and contextual levels (McCallum et al., 2017).

At the individual level, personal factors such as teacher self-efficacy, optimism, gratitude, or mindfulness have found to be positively associated with teacher well-being (Jennings et al, 2013; Kern et al., 2014; Ross et al., 2012; Wang \& Hall, 2019). Teachers who possess stronger coping strategies and supportive personality traits are also more likely to report higher levels of occupational well-being (Bermejo-Torjo et al., 2016; Burns \& Machin, 2011).

Positive interpersonal relationships at work have also been shown to predict overall well-being among teachers. Connection to colleagues can foster a sense of belonging and facilitate positive mental health and well-being among teachers (Jacobsson et al., 2016; Hobson \& Maxwell, 2017; Owens, 2016). The quality and character of a school in which teachers work also influences teacher well-being (Cohen et al., 2009). Positive school climates and enabling working conditions have been associated with teacher retention and decreased teacher burnout (Ross et al., 2012; Skaalvik \& Skaalvik, 2018).

In sum, teacher well-being is influenced by a variety of factors and is most successful when using a holistic approach to support each level of the educational system (McCallum et al., 2017). Making changes in individuals when the system is part of the problem leaves basic structures intact, and outcome behaviors are mostly addressed. It is critical that researchers and policymakers consider changes for teachers rather than in teachers (Berryhill et al., 2009).

\section{Teacher Resilience}

Resilience has typically been defined as an individuals' capacity to adapt or even thrive in spite of adversity (Beltman et al., 2011). This may be in response to a specific traumatic event or one's daily response to accumulating challenges (Clara, 2017). More nuanced understandings of resilience have suggested that resilience is a complex process resulting from the interplay between risk and protective factors at both the individual and environmental levels and those who exhibit resilience are more likely to experience professional engagement, motivation, satisfaction, and well-being (Beltman, 2015; Mansfield et al., 2016; Ungar, 2012). 
At the individual level, teachers who exhibit resilient traits, such as a sense of efficacy and accomplishment, flexibility, a sense of purpose, or use of coping strategies, may be more likely to persevere in spite of challenging circumstances (Mansfield et al., 2012). In contrast, teachers who have greater difficulty coping with the emotional demands of their work are at higher risk of stress and burnout (Mansfield et al., 2012).

Social ecological perspectives of resilience emphasize the significant impact of the environment in which individual teachers are situated (Unger, 2012). Environmental contributors can include support for new teachers (e.g. mentors), support from colleagues and administrators, school culture, and working with students (Ainsworth \& Oldfield, 2019; Mansfield et al., 2012).

Critical perspectives of teacher resilience (e.g. Johnson \& Down, 2013 \& Price et al., 2012) also emphasize the importance of context, questioning whether the term "resilience" has become a "means to enable overworked teachers" to cope with the intense pressures of capitalism and globalization rather than attempting to resist or change toxic systems (Price et al., 2012, p. 84). Cultivating teacher resilience should involve greater attention to the structural and institutional nature of teachers' work, including school management and culture, rather than individually targeted interventions (Ainsworth \& Oldfield, 2019). Individual factors certainly contribute to teachers' ability to bounce back from adversity, but the context in which teachers work may be even more important (Ainsworth \& Oldfield, 2019).

\section{Teacher Well-Being During COVID-19}

Under normal circumstances, teaching is cited as one of the most stressful professions (Johnson et al., 2005). However, the prolonged COVID-19 crisis has posed many new challenges for teachers such as a lack in technological and pedagogical skills, declining student engagement and attendance, and increased levels of stress (Diliberti et al., 2021; McIntyre et al., 2020). Stress has been exacerbated among teachers in high-poverty and majority Black schools, who have reported more severe challenges and higher levels of stress than teachers in well-resourced schools (Kraft et al., 2020). Many teachers have also reported a large drop in their sense of success during the pandemic (Kraft et al., 2020). This has forced many to consider leaving the field and district leaders worry about longer term consequences on teacher retention and teacher pipelines (Carver-Thomas et al., 2021; Diliberti et al., 2021).

Teacher well-being during COVID-19 has been the product of individual factors (e.g., coping strategies) and supportive working conditions (e.g., strong leadership). Those with more supportive working environments (e.g., strong leadership and meaningful collaboration) reported less stress and more success than those who worked in less supportive environments (Kraft et al., 2020). Teachers' own unique coping strategies have also played a role in their ability to navigate the stress of remote teaching during the pandemic - those who use proactive problem-solving strategies report higher positive psychological outcomes than those who use avoidance strategies (McIntyre et al., 2020).

\section{THEORETICAL FRAMEWORK}

This study is framed by two core conceptual models: the job-demands-resource model of well-being and the hierarchy of needs theory of motivation.

\section{Job Demands-Resource Model of Well-Being}

The job demands-resource model is a broadly defined but widely used framework for explaining individual's well-being at work (Bakker \& Demerouti, 2014; Schaufeli \& Taris, 2014). In this model, work environments (e.g., schools) and job characteristics (e.g., teaching) fall into one of two categories: job demands and job resources (Yin et al., 2018). An individual's workplace well-being is the balance of all job demands and job resources. How balanced or imbalanced job demands, and resources are critical for predicting individual well-being, occupational engagement and performance, and burnout.

Job demands include physical, psychological, social, or organizational aspects of the job including workload demands, emotional demands, or job insecurity (Yin et al., 2018). Job resources are the physical, psychological, social, or organizational aspects of a job that can support performance. These can "reduce 
job demands and associated physiological and psychological costs (Bakker \& Demerouti, 2007, p. 312). Some JD-R models also include personal psychological characteristics such as an individual's ability to manage stress (Yin et al., 2018).

This model has been applied widely in occupation literature and more recently, to teacher well-being (e.g., Bermejo-Toro et al., 2019). For teachers, there are a number of job-specific factors that are considered demanding including grading, planning, or emotional demands (Yin et al., 2018). Job-specific resources may include positive school climates or joy from working with children. Trust in colleagues and reappraisal as a personal coping strategy, for example, have been positively associated with enthusiasm and contentment among teachers whereas suppression as a coping strategy has been associated with anxiety and depression (Yin et al., 2018).

Hierarchy of needs. Maslow's hierarchy of needs theory has frequently been applied to studies of human behavior and motivation (Maslow, 1943). In this five-stage model, individuals are able to flourish and reach their full potential when basic physiological needs, safety needs, belongingness and love needs, and esteem needs are satisfied. These five core needs are often grouped into deficiency and growth needs. Deficiency needs arise as the result of deprivation and can be motivating when they are unmet. Alternatively, growth needs are not in response to a lack of something but from a desire to grow or improve on a personal level. The hierarchy of needs are not rigid as the pyramid suggests but can differ based on certain circumstances of preferences. In the case of teacher well-being and work satisfaction, teachers theoretically can achieve their full potential and creatively express themselves once other basic needs are met, including a sense of accomplishment.

\section{METHODS}

This study was a longitudinal qualitative study that employed recurrent cross-sectional analysis to investigate teacher well-being during COVID-19 at two time points (June 2020 and March 2021).

\section{Research Questions}

Researchers were interested in exploring how teacher well-being during the pandemic shifted over time and changes in response by individuals and schools to the prolonged crisis.

1. What do teachers identify as primary barriers to and facilitators of well-being while teaching during the COVID-19 pandemic?

2. How did perceptions of facilitators and barriers to teacher well-being change over time?

\section{SAMPLE}

A total of 49 teachers participated in the qualitative study at time 1; twenty-five of these teachers also participated at time 2. All participants were: (a) at least 18 years old; (b) were teaching full time; and (c) taught in grades K-12. This study was approved by the university's Institutional Review Board (IRB). Surveys were completed online, and interviews were conducted via video conference (e.g., Zoom).

A vast majority of participants were female (96\%), but teachers represented a range of ages, years of teaching experience, school setting, and grade level (Table 1). At time 1 all teachers were teaching remotely; at time $2,26 \%$ of teachers reported teaching in-person only, 34\% were only teaching remotely, and $38 \%$ were using a hybrid model of both in-person and virtual teaching. 


\section{TABLE 1 \\ PARTICIPANT DEMOGRAPHICS \\ $\mathbf{n}=\mathbf{2 5}$}

\begin{tabular}{lllll}
\hline Gender & Age & Years Teaching & School Setting & Grade Level \\
\hline $\mathrm{F}=24(96 \%)$ & $20 \mathrm{~s}=1(4 \%)$ & $0-2$ years $=1(4 \%)$ & Public $=19(76 \%)$ & K-2nd $=12(48 \%)$ \\
$\mathrm{M}=1$ & $30 \mathrm{~s}=10(40 \%)$ & $2-5$ years $=7(28 \%)$ & Charter $=2(8 \%)$ & $3-5$ th $=5(20 \%)$ \\
& $40 \mathrm{~s}=6(24 \%)$ & $5-10$ years $=8(32 \%)$ & Private $=4(16 \%)$ & $6-8$ th $=4(16 \%)$ \\
& $50 \mathrm{~s}=6(24 \%)$ & $10+$ years $=9(36 \%)$ & & $9-12$ th $=4(16 \%)$ \\
& $60 \mathrm{~s}=2(8 \%)$ & & & \\
\hline
\end{tabular}

\section{DATA COLLECTION}

A team of two researchers collected qualitative data at two points. Participants were recruited using snow-ball convenience sampling, where the first subjects recruited to the sample group provided multiple referrals (Creswell, 2013). Participants were assigned a unique participant ID to anonymously track responses over time. These IDs were emailed directly to participants with a link to the survey.

Teachers $(n=49)$ responded to survey questions at time 1 . Teachers were asked to talk about factors that supported their well-being at the individual and school level during the pandemic on a short-answer survey. Teachers were asked about their perceptions of well-being, their capacity to deliver high quality instruction, individual strategies they used to manage stress, school or district support related to teacher well-being, and what they think their districts/schools could be doing. Approximately one-third $(n=16)$ of these participated in additional, optional semi-structured interviews. Researchers conducted virtual interviews that lasted 30-60 minutes. Teachers were asked to describe their experiences related to wellbeing during the spring of 2020 (e.g., "how has remote teaching impacted your well-being?"). Interviews were audio recorded and transcribed by the first two authors.

At time 2, researchers sent a longer short answer survey rather than requiring a survey and additional interviews. This was done to protect teachers' time as this data collection period was during a time when many schools in the United States were transitioning back to in-person learning. Researchers sent surveys to the original 49 participants and 25 teachers $(51 \%)$ responded at time 2 . For the purpose of consistency, researchers only analyzed short-answer responses from teachers who participated at both time points $(n=$ 25).

Several measures were taken to establish trustworthiness throughout the study including member checking and triangulation. Additionally, interview and survey questions were checked by content experts and participants were asked to review interview transcripts for clarity (Lincoln \& Guba, 1985)

\section{DATA ANALYSIS}

Data was analyzed using recurrent cross-sectional analysis in which themes across two time points were compared (Grossoehme \& Lipstein, 2016). This approach can also be thought of as "a series of smaller studies" at each time point followed by a second analysis that focuses on differences and similarities between time points (Grossoehme \& Lipstein, 2016, p. 3).

Data from time 1 was analyzed before data was collected at time 2 . Teacher interviews and short answer survey responses were coded line by line by both researchers to develop a preliminary codebook, which was applied to all data at time 1. Following data collection at time 2, researchers applied the original codebook to transcripts to determine if any adjustments needed to be made. Minor changes were made to the codebook. Researchers then applied the revised codebook to transcripts of short-answer responses at time 2. Researchers coded transcripts separately and then together until $100 \%$ consensus was reached. Next, researchers used a data matrix to display codes and quotes from time 1 and time 2 side-by-side. This aided 
constant comparison analysis to identify changes over time. Finally, researchers used thematic analysis to look across codes over time to identify key findings.

\section{RESULTS}

\section{Findings}

Teachers reported a number of barriers and facilitators to well-being while teaching during the COVID19 pandemic at individual and contextual levels (Table 2). Core themes across participant experiences over time are also discussed.

TABLE 2

BARRIERS AND FACILITATORS OVER TIME

\begin{tabular}{|c|c|c|}
\hline Themes & Time 1 & Time 2 \\
\hline \multicolumn{3}{|c|}{ Individual Barriers } \\
\hline Lack of Boundaries & $\begin{array}{c}\text { "I have no separation between } \\
\text { home and school." (7653) }\end{array}$ & $\begin{array}{c}\text { "It has taken away from my } \\
\text { family, my home and my ability } \\
\text { to support my own school age } \\
\text { child." (9788) }\end{array}$ \\
\hline Disconnected & $\begin{array}{c}\text { "Seeing my students less means } \\
\text { feeling less fulfilled in my work." } \\
(5695)\end{array}$ & $\begin{array}{c}\text { "The lack of connection with } \\
\text { colleagues and kids is } \\
\text { draining." (2378) }\end{array}$ \\
\hline Low Efficacy & $\begin{array}{c}\text { "I also feel less accomplished } \\
\text { and successful in my job." } \\
\text { (8139) }\end{array}$ & $\begin{array}{l}\text { "I miss the satisfaction of feeling } \\
\text { like I am doing my job well." } \\
\text { (8139) }\end{array}$ \\
\hline $\begin{array}{c}\text { Emotional/Physical Well- } \\
\text { being }\end{array}$ & $\begin{array}{c}\text { "Depressed, scared/nervous for } \\
\text { my family." (3834) }\end{array}$ & $\begin{array}{l}\text { "Increased stress and } \\
\text { depression." (3834) }\end{array}$ \\
\hline \multicolumn{3}{|c|}{ Individual Facilitators } \\
\hline Self-care Strategies & $\begin{array}{l}\text { "Getting outside has been } \\
\text { helpful" (8139) }\end{array}$ & $\begin{array}{c}\text { "Breathing! As I have taught it } \\
\text { to the kids, I find it helps me } \\
\text { every time!" (4443) }\end{array}$ \\
\hline Well-being Dispositions & $\begin{array}{c}\text { "Accept that I am doing the best } \\
\text { that I can and adopt a growth } \\
\text { mindset." (2624) }\end{array}$ & "It is what it is mindset." (5130) \\
\hline Leaning on Others & $\begin{array}{c}\text { "I have a teammate who I am } \\
\text { planning with and she is my } \\
\text { lifeline." (7653) }\end{array}$ & $N / A$ \\
\hline \multicolumn{3}{|c|}{ Contextual Barriers } \\
\hline Heightened Uncertainty & $\begin{array}{l}\text { "Lots of paperwork, constantly } \\
\text { changing expectations." (5695) }\end{array}$ & $\begin{array}{c}\text { I need "a plan they can stick to." } \\
\text { (9788) }\end{array}$ \\
\hline Unrealistic Expectations & $\begin{array}{l}\text { "The work level they expect } \\
\text { (including feedback direct to } \\
\text { students and google meet times) } \\
\text { takes longer than that." (7653) }\end{array}$ & $\begin{array}{l}\text { "My workload has tripled. The } \\
\text { grading platform doesn't work } \\
\text { and things keep changing } \\
\text { constantly." (9788) }\end{array}$ \\
\hline
\end{tabular}




\begin{tabular}{|c|c|c|}
\hline Limited Teacher Input & $\begin{array}{l}\text { "It doesn't seem like teacher } \\
\text { well-being has factored much } \\
\text { into planning or administrative } \\
\text { discussion/strategy." (8682) }\end{array}$ & $\begin{array}{c}\text { "They need to involve teachers } \\
\text { in all important decisions, } \\
\text { because we are the only people } \\
\text { who have any firsthand } \\
\text { experience in how to do this." } \\
\text { (8682) }\end{array}$ \\
\hline Lack of Flexibility/ Autonomy & $\begin{array}{c}\text { "I feel like I'm forced to do a } \\
\text { 'one size fits most' approach } \\
\text { which is not the way I usually } \\
\text { teach." (8622) }\end{array}$ & $\begin{array}{c}\text { "I need them to stop being so } \\
\text { focused on testing and data." } \\
\text { (1886) }\end{array}$ \\
\hline \multicolumn{3}{|c|}{ Contextual Facilitators } \\
\hline Empathetic Leadership & $\begin{array}{c}\text { "My superintendent sends the } \\
\text { best supportive emails every } \\
\text { Friday." (2715) }\end{array}$ & $\begin{array}{c}\text { "We're not allowed to make } \\
\text { changes to that model because } \\
\text { of state rules. Our admin is } \\
\text { trying!!" (2378) }\end{array}$ \\
\hline Having a Team & $\begin{array}{c}\text { "A general 'we are all rowing in } \\
\text { the same boat.", (5518) }\end{array}$ & "Relationship building." (3834) \\
\hline Increased Resources & $\begin{array}{l}\text { "They are paying us extra over } \\
\text { the summer and working on } \\
\text { childcare solutions that will } \\
\text { begin before the start of the } \\
\text { school year to support us as we } \\
\text { head back." (8542) }\end{array}$ & $\begin{array}{c}\text { "They are creating more content } \\
\text { for us and that has helped a } \\
\text { ton!" (7653) }\end{array}$ \\
\hline
\end{tabular}

\section{Barriers at the Individual Level}

Teachers described many barriers at the individual level that prevented them from having a high sense of well-being during Covid-19. Barriers at the individual level included four common stressors across participants: (1) a lack of boundaries; (2) disconnect or loss of purpose; (3) low efficacy; and (4) a general decline in physical and emotional well-being.

\section{Lack of Boundaries}

A loss of boundaries between work and home life were shared by many of the 25 participants, but particularly among parents with young children. At time 1, teachers who were parents felt "beyond stressed" with being a teacher and a full-time parent" (3270). One teacher shared she was either "failing at their job or failing as a mother or both," expressing that doing both "is impossible" (8542). At time 2, participants made similar statements, such as: "remote [teaching] is no problem if you don't have a family or kids...you literally cannot work from home" (3270) or, "it has taken away from my family, my home, and my ability to support my own school age child" (9788). Others said they wake up "insanely early to work" and felt "that work is never finished," suggesting that setting boundaries around work was continuously a challenge $(8542,1164)$. From time 1 to time 2 , teachers, particularly those with young children, continued to feel they had difficulty setting appropriate boundaries and were overwhelmed by responsibilities.

\section{Disconnect: Loss of Purpose}

Many participants reported feeling isolated from colleagues and students. This disconnect contributed to a lack of purpose in work. During time 1, teachers felt that their professional fulfillment was "nonexistent" (1062) and that "seeing students less meant feeling less fulfilled at work" (5695). At time 2, teachers continued to feel "isolated" (7653). May shared that, "it was hard to connect with students" (7220) and the lack of connection "was draining" (2378). Unfortunately, feeling disconnected and unfulfilled remained a challenge for teachers over time. 


\section{Low Efficacy (Technological Challenges, Hybrid Teaching)}

Experiencing decreased teaching efficacy was shared across time. Most teachers did not feel successful teaching remotely. At time 1, teachers expressed concern over students' ability to access and participate in distance learning, which "added additional stress" related to the reduced "impact that teachers may have on students learning" (3823). This made many "feel less accomplished and successful in their job" (8139).

At time 2, many teachers (38\%) talked about the challenges of hybrid learning and their ability to reach students. One teacher stated that, "I feel like I had [finally] hit a stride when things were only remote but balancing hybrid has led to a regression" (8139). Another participant shared, "hybrid has made me a frustrated beginner all over again" (8542). Additionally, teachers in time 2 talked about the amount of work and time that goes into teaching remotely or in hybrid classrooms. They expressed concern that there is "a lot more work and you do not see the benefits as clearly as you do with kids right in front of you" (8622), and others said, "their ability to teach effectively has decreased" (1026). There were few changes in teacher efficacy over time. Many teachers reported that once they got the "hang of remote learning," learning requirements or situations changed, making them feel less effective.

\section{Emotional and Physical Well-Being: General Anxiety and Loss of Control}

All teachers reported feeling increasingly uncertain, stressed, and overwhelmed during this time. Both physical well-being and social-emotional well-being decreased for many. Many teachers reported that traditional self-care strategies such as exercise or getting outside have done little to mitigate the stress of teaching during the pandemic. One teacher in time 1 stated that they felt "depressed, scared, and nervous for [their] family" (3834). Another teacher stated there "have been so many more unknowns" which made them feel "less in control" (2378). Teachers in time 2 illustrated the same concerns; they stated that, "the workload is more, and the future is scary" (6556) and wished "the future was more certain" (7653).

Concern about second-hand trauma and the lack of clarity about the future have also been on teachers' minds. One teacher stated, "the issue of vicarious trauma...teachers experience a lot of stress when their students are in crisis and the systems are not reliably there to help" (8682). Others shared deep concern for instability in their students' lives and the loss of learning and social development opportunities. Over time, teachers continued to feel an immense sense of anxiety and loss of control related to their own physical and mental health.

\section{Barriers at the Contextual Level}

Teachers also described barriers or obstacles that contributed to overall well-being at the contextual level (e.g., school/district). These included: (1) heightened uncertainty; (2) unrealistic expectations; (3) limited teacher input; and (4) lack of flexibility and autonomy.

\section{Heightened Uncertainty}

Of the 25 participants, uncertainty, and lack of clarity around school policies and changes in expectations were frequently discussed. At time 1, one teacher stated that "the constant changes in grading policies is stressful and I do not feel like my principal is supporting me" (7220). Another teacher said expectations were "constantly changing," and there was very little support from administrators or the central office $(5695,2624]$. One teacher felt the administration provided little clarity around simple administrative challenges such as needing to take a day off and felt that there was a lot of "talk" but few "actionable steps" to support teachers (5695).

At time 2, most teachers faced the same feelings of uncertainty from their school and district leadership. Some reported there were "no clear directions" related to things like expectations for "children with special needs" (5130) or substitute policies. Others felt strongly that administrators needed to have a plan and "stick to it" (9788). Many reported lack of clarity around grading policies, testing, safety protocols, or special education compliance. Although one teacher shared that things calmed down over time, saying, "It's better. Last spring was so chaotic, and there was much less interaction with students online" (8682), this was not the case for most. In general, teachers did not experience greater clarity or better communication from leaders over time and this created great uncertainty about their jobs, responsibilities, and school policies. 


\section{Unrealistic Expectations: Want More With Less}

Teachers reported increased workload despite few changes in the pandemic situation. Many felt that administrators wanted more with less. For example, some shared that district tried "to do business as usual" but that "has felt impossible to teachers" (6132). In the beginning of the pandemic, teachers stated that they were expected to work normal hours (not overtime) even though providing meaningful lessons and feedback to students virtually took far longer (7653). Multiple virtual meetings were challenging for teachers, and some felt the "administration has not been understanding" (2624).

At time 2, teachers similarly stated that "more is being asked of us now," and some felt that "there was more understanding of pandemic pressures in the beginning" (8622). Others stated that their workload tripled and yet they still needed "to be ready to pivot at any given time" $(9788 ; 8682 ; 6132)$. As the pandemic progressed, and teachers taught in varied formats, expectations rose, and administrators put increasingly more demands and pressure on teachers. At both time points, teachers felt that they were asked to do too much with few resources and as the year went on, this feeling intensified.

\section{Limited Teacher Input}

Teacher voice and not being "seen" as professionals was a theme discussed throughout the pandemic. Many participants shared that they did not feel "valued" or that their experiences and perspectives mattered to decision makers. At time 1, one teacher said their administration had not done anything for the teachers "except a couple of weekly meetings, and some emails during teacher appreciation week...it doesn't really seem like teacher well-being has been factored into planning or administrative discussion/strategy" (8682). Teachers shared that their perspectives were not taken into consideration regarding student expectations, grading policies, or comfort and safety with returning to work.

At time 2, teachers felt there were even fewer outlets for teacher input. One teacher stated, "I do not feel valued as a professional. I feel like a pawn in a political game" and that they "have less confidence in the board of education doing the right thing" for employees (7220). Some were frustrated "that they are requiring us to go back into schools right before being vaccinated" and even felt threatened, sharing "the governor threaten[ed] to revoke our licenses if we don't return to work...even with health concerns" (7220). Others felt that administrators needed to do a better job of involving teachers in all important decisions, because "we are the only people who have any firsthand experience in how to do this" (8682). Over time, there was little to no change in opportunities for teacher voice and input related to their jobs. Many felt unheard, unappreciated, and unsupported by decision makers.

\section{Lack of Flexibility and Autonomy}

Teachers felt that they had little autonomy or flexibility in their work despite teaching in unprecedented circumstances. For example, one teacher at time 1 stated that, "I feel like I am forced to do a 'one size fits most' approach which is not the way I usually teach" (8622). At time 2, teachers felt that administration "could relax about making sure we are strictly sticking to schedules" (1886). Another said, "flexibility was important but often lacking" (3270). For example, she said, "Monday morning meetings are a bit early...this meeting is so inconvenient, I am trying to get my 2 toddlers out to daycare" (3270). Teachers felt pressure to adhere to rigid schedules or expectations in spite of teaching under such challenging circumstances. Another said, "our state regulations make it hard for us to do what we know is right for our families" (2378). If anything, these feelings intensified from time 1 to time 2, with some reporting that there was more empathy and understanding at the beginning of the pandemic and more pressure to meet traditional standards a year later.

\section{Facilitators at the Individual Level}

Teachers also described strategies that have helped them increase or maintain their overall well-being during COVID-19. Individual facilitators within the context of this study included: (1) self-care strategies; (2) well-being dispositions; and (3) leaning on others. 


\section{Self-Care Strategies}

Many teachers in this study reported that self-care strategies such as exercise, getting outside, spirituality, or therapy helped them cope with the stress of teaching and manage feelings of isolation (8139; $8555 ; 1164)$. Some teachers at time 1 even described having more time for self-care and sleep $(8139 ; 9788$; 3310). Others discussed sticking to a schedule and ensuring they kept a routine. Being able to "say no to things" (8682) and "scheduling time on the calendar for each task" (8622) helped them manage stress. Selfcare strategies remained consistent throughout the pandemic, with many teachers using positive outlets or proactive coping strategies to manage increasing levels of stress.

\section{Well-Being Dispositions}

In addition to self-care strategies to manage stress during the pandemic, many teachers reported that cognitive strategies and positive attitudes helped them maintain a sense of well-being. For some this meant intentionally finding "meaning and purpose" or "adopting a growth mindset" $(2624 ; 5130)$. One teacher stated at time 1 shared that teaching online was a "silver-lining" because it "provided opportunities for learning and growth" (9136). Teachers found opportunities to connect with parents more frequently, work more closely with some students one-on-one, or even "engage with students better" (3310). Some even stated that a growth mindset and positive mindset led them to additional professional development classes to further their learning. At time 2, teachers reported that adopting an attitude of acceptance, sharing that "understanding that there are some things that I cannot control" (2624) helped them cope. Others felt they had settled "into a new normal" $(7653 ; 5412)$. There were few changes in well-being dispositions over time, but in general teachers who found meaning and purpose in their work or had a level of acceptance tended to describe their situations more positively.

\section{Leaning on Others and Community}

Teachers only shared that they proactively sought out others in their community to maintain a sense of well-being during time one. In the beginning of the pandemic, teachers relied heavily on their school community or family for support. Teachers talked about how colleagues helped them navigate virtual learning formats: "[We] really were there for each other...If someone was overwhelmed it was like, we can work this out" $(1164 ; 7653)$. Others described frequent team check-ins as beneficial, sharing "we have a group meeting where everybody just checks in everyday and...makes sure everybody is okay" (1686). Some teachers talked about relying on their family to help with childcare, cooking, housework, or technological support. Although this was an important facilitator of well-being at time 1, teachers did not discuss the importance of these social networks at time 2 .

\section{Facilitators at the Contextual Level}

Teachers also described facilitators, or strategies that have helped them increase their overall well-being during the pandemic at the contextual level. They spoke of three major themes: (1) empathetic leadership; (2) having a team; and (3) increased resources for teachers.

\section{Empathetic Leadership}

Teachers discussed empathetic leadership from administrators as an important driver of their wellbeing, particularly during time 1 . Some teachers shared that simple email communication made them feel appreciated: "my superintendent sends the best supportive, empathetic, and inspiring emails every Friday" $(2715,1886,1164)$. Others said that they felt that "the support was there if $i$ want it" (8139) and "that [leaders] were thoughtful about family and personal time" (2378).

At time 2, teachers felt that administrators tried to be supportive but had to also balance regulations or expectations from "above." As one teacher said, "we are not allowed to make changes to the model because of state rules. Our admin is trying!" (2378). A few teachers at time 2 mentioned that they appreciated specific positive feedback (4443) and acknowledgement of those doing all the work right now (8555). Teachers during time 1 had more positive examples of empathetic leadership, while in time 2, they also recognized the tension between leaders' best efforts to demonstrate empathy and state policies. 


\section{Having a Team}

Having supportive colleagues to help navigate challenging times was discussed at length during time 1. Feeling that "we are all rowing in the same boat" (5518) was important to teachers. One teacher described how colleagues helped each other navigate new virtual formats (1164). Another specifically mentioned that she felt very isolated and was used to collaborating with and getting support from other teachers. She said, "I have a full time assistant, and I don't know if i could have done it without her. We were in constant contact"(1886). Another shared, "I feel connected even though we are not together. We have Microsoft Teams, so we still see each other when we need to. And now that school is out, it's just me and two other teachers that are here this summer- but they still keep the group going" (7461). During time 2, only one teacher specifically discussed relaying on their team by sharing relationship building activities that their school has put in place (3834).

\section{Increased Resources for Teachers}

Teachers reported that increased resources for well-being and teaching were helpful. These included adult social emotional learning opportunities and mental health resources, such as administrators offering well-being initiatives, wellness checks, and information about counseling services $(9788 ; 3270 ; 4443)$. Teachers also talked about financial resources such as raises for summer work or childcare solutions as supporting their well-being and perceptions of support (8542). At time 2, teachers discussed physical resources (e.g., masks, cleaning supplies, and COVID-19 testing; 8542) and vaccines $(5130,7220 ; 6132)$ as being resources they needed before they felt safe to come back to work. At time 1, teachers discussed the importance of pedagogical tools to teach online and mental health support whereas at time 2, teachers talked more about physical resources needed to feel safe upon returning to in-person instruction.

\section{Longitudinal Comparison}

Longitudinal comparisons suggest that there were limited changes from time 1 to time 2 except in a few areas including heightened uncertainty, unrealistic expectations, leaning on others, and resources. At time 1 , teachers reported challenges adapting to teaching online and navigating the uncertainty of the pandemic but generally felt more supported by their administrators or their "team." Unfortunately, at time 2 , teachers found it difficult to keep up with increasing demands regarding teaching and learning despite few changes in the pandemic. Teachers felt that unrealistic expectations from administrators increased over time, instead of decreased. Teachers repeatedly discussed how administrators were making them do more with less and that the pressure facing teachers was unsurmountable. This led to a lack of clarity regarding expectations and frustration with school or district policies.

Interestingly, teachers spoke at length about the importance of social connections at time 1 as the pandemic was just beginning, and schools and administrators were trying to figure out how to support one another through what was thought to be a short-term emergency. However, social connection was rarely discussed at time 2. Finally, teachers talked about the resources they received from their leaders or district to support mental health at time 1 , but at time 2 they talked more about what they physically needed to feel safe at school.

\section{DISCUSSION}

Looking across facilitators and barriers at individual and contextual levels over time, three key themes emerged regarding teachers' well-being: (1) Individual well-being strategies barely mitigate the stress teachers are feeling as the result of teaching during the pandemic; (2) leadership continues to be an important contributor to teachers' perceptions of their well-being; and (3) teachers want to be heard, safe, and valued. These themes also support the job-demands resource model and hierarchy of needs framework.

\section{Individual Well-Being Strategies}

Although many teachers talked about utilizing self-care strategies such as exercise, mindfulness, or setting boundaries, these did not entirely alleviate feelings of heightened stress or helplessness. Teachers 
shared that taking care of themselves was important, but that they still experienced very high levels of anxiety or frustration with their job because they did not have enough support or find the same sense of fulfillment when teaching remotely. These strategies may help reduce stress and temporarily improve wellbeing but were not enough to overcome the very real challenges of teaching during a prolonged pandemic.

\section{Leadership}

Teachers frequently cited school and district leadership as either facilitating or inhibiting their wellbeing. In cases where leaders were empathetic and understanding, teachers felt supported. However, more often than not, teachers reported that unrealistic expectations and lack of clarity from school or district leadership contributed to increased stress and decreased well-being.

\section{Need to Feel Valued}

A year into the pandemic, teachers felt there had been little change in their stress levels because their needs were not being heard or valued by local decision makers. At a very basic level, teachers wanted to feel safe returning to the classroom. At the time of data collection, teachers had not yet been vaccinated in a majority of schools and many shared that health and safety was their main priority. Over time, teachers felt that their voices had not been incorporated into major decisions, such as grading policies, state testing requirements, scheduling, or teaching format (e.g., hybrid). This made many feel undervalued as professionals and human beings.

\section{Job-Demands-Resources Model}

As previously discussed, psychological resources can be an important component of workplace wellbeing. However, for many teachers during the pandemic, individual resources (self-care, positive attitudes) were not enough to overcome increased workplace demands, particularly when demands were not met with adequate resources. Unfortunately, many recommendations teachers received to support their mental health fell under the domain of "individual strategies." To adequately meet the demands of teaching during such stressful times, additional external support is needed. This may include job-related resources such as school connectedness. Positive, empathetic leadership, for example, can be a significant job-resource, particularly during challenging times and when facing uncertainty.

\section{Hierarchy of Needs}

At the most basic level, teachers perceived that their need for safety was not being met, let alone their need for belongingness. Teachers also felt unsuccessful and their need for esteem or a feeling of accomplishment has, for the most part, been unmet after a year of teaching during the pandemic. Many shared that they felt like "beginners" and had a decreased sense of efficacy. Without basic needs being met, teachers did not report "self-actualization or fulfillment." Considering teacher retention and well-being, this is quite problematic. Many teachers enter the profession because they have a desire for meaning and fulfillment in their work and leave because this has not been realized. After a year of feeling that even the most basic needs are not being met by the job, let alone growth needs associated with self-actualization, district leaders and policymakers have reason to be concerned about turnover and attrition rates. Although this study only included 25 teachers, they represented a wide range of school settings, grade levels, years of experience, and age. If teachers' experiences in this study mirror national trends related to well-being, there is much work to be done to support a return to "normal" schooling.

\section{LIMITATIONS}

Participants represented a range of school settings and experience, but findings may not be generalizable to all teachers. Demographic data collection was limited. Although short-answer surveys were collected at two time points, interviews were only conducted at time 1 in order to respect participant's time. Additionally, our full sample of 25 teachers represented only half of all original participants who completed short-answer surveys at time 1 . Those that did not participate at time 2 may in some way be different from 
those who participated at both time points. The results of this study should be interpreted with these limitations in mind.

\section{CONCLUSION}

Although many teachers in this study demonstrated great resilience in response to a year of teaching during a global pandemic, they were still operating in less-than-ideal conditions and in highly stressful contexts. Over time, teachers tended to feel less supported by their administrators and more worn down by the job. In cases where teachers reported no changes in their well-being, or even improvements over time, they often had high levels of school-based support including empathetic leaders, flexibility, opportunities for input, and strong connections to other staff. As schools transition back to in-person learning environments, it is critical that teachers' needs be prioritized. This may include individually targeted support to help teachers manage stress and improve well-being but also school and district wide strategies that emphasize a culture of care, collaboration, and opportunities for teacher input.

\section{REFERENCES}

Acton, R., \& Glasgow, P. (2015). Teacher wellbeing in neoliberal contexts: A review of the literature. Australian Journal of Teacher Education, 40(8). http://dx.doi.org/10.14221/ajte.2015v40n8.6

Aelterman, A., Engels, N., Van Petegem, K., \& Verhaeghe, J. (2007). The well-being of teachers in Flanders: The importance of a supportive school culture. Educational Studies, 33(3), 285-298. https://doi.org/10.1080/03055690701423085

Ainsworth, S., \& Oldfield, J. (2019). Quantifying teacher resilience: Context matters. Teaching and Teacher Education, 82, 117-128. https://doi.org/10.1016/j.tate.2019.03.012

Bakker, A., \& Demerouti, E. (2007). The job demands-resources model: State of the art. Journal of Managerial Psychology, 22, 309-328. doi:10.1108/02683940710733115

Beltman, S., Mansfield, C., \& Price, A. (2011). Thriving not just surviving: A review of research on teacher resilience. Educational Research Review, 6(3), 185-207. doi:10.1016/j.edurev.2011.09.001

Bermejo-Toro, L., Prieto-Ursúa, M., \& Hernández, V. (2016). Towards a model of teacher well-being: Personal and job resources involved in teacher burnout and engagement. Educational Psychology, 36(3), 481-501. https://doi.org/10.1080/01443410.2015.1005006

Berryhill, J.C., Linney, J., \& Fromewick, J. (2009). The effects of education accountability on teachers: Are policies too-stress provoking for their own good? International Journal of Education, 4, 114. doi:10.22230/IJEPL.2009V4N5A99

Billingsley, B., \& Bettini, E. (2019). Special Education Teacher Attrition and Retention: A Review of the Literature. Review of Educational Research, 89(5), 697-744. https://doi.org/10.3102/0034654319862495

Bricheno, P., Brown, S., \& Lubansky, R. (2009). Teacher wellbeing: A review of the evidence. London, England: Teacher Support Network. Retrieved from https://www.scribd.com/doc/25759578/Teacher-Wellbeing-A-research-of-the-evidence

Brunsting, N.B., Sreckovic, M.A., \& Lane, K.L. (2014). Special education teacher burnout: A synthesis of research from 1979 to 2013. Education \& Treatment of Children, 37(4), 681-711. doi:10.1353/etc.2014.0032

Burns, R.A., \& Machin, M.A. (in press). (n.d.). Moving beyond the pleasure principle: Within and between-occasion effects of employee eudemonia within a school organizational climate context. Journal of Vocational Behavior, 80, 118-128. doi:10.3389/fpsyg.2019.02132

Carver-Thomas, D., \& Darling-Hammond, L. (2017). Teacher turnover: Why it matters and what we can do about it. Learning Policy Institute. Retrieved from https://learningpolicyinstitute.org/sites/default/files/productfiles/Teacher_Turnover_REPORT.pdf 
Cassidy, D.J., King, E.K., Wang, Y.C., Lower, J.K., \& Kintner-Duffy, V.L. (2016). Teacher work environments are toddler learning environments: Teacher professional well-being, classroom emotional support, and toddlers' emotional expressions and behaviours. Early Child Development and Care, 187(11), 1-13. https://doi.org/10.1080/03004 430.2016.1180516

Clarà, M. (2017). Teacher resilience and meaning transformation: How teachers reappraise situations of adversity. Teaching and Teacher Education, 63, 82-91. https://doi.org/10.1016/j.tate.2016.12.010

Cohen, J., \& Geier, V.K. (2010). School climate research summary [January 2010]. Retrieved from http://www.schoolclimate.org/climate/schoolclimatebriefs.php

Creswell, J.W. (2014). Research design: Qualitative, quantitative and mixed methods approaches (4th ed.). Thousand Oaks, CA: SAGE Publications.

Denham, S.A., Bassett, H.H., \& Zinsser, K. (2012). Early childhood teachers as socializers of young children's emotional competence. Early Childhood Education Journal, 40(3), 137-143. https://doi.org/10.1007/s10643-012-0504-2

Dilbirti, M., Schwartz, H., \& Grant, D. (2021). Stress topped the reason why teachers quit even before COVID-19. Rand Corporation. Retrieved from https://www.rand.org/pubs/research_reports/RRA1121-2.html\#: :text=Almost $\% 20$ half $\% 20$ of $\%$ 20the $\% 20$ public,of $\% 20$ the $\% 20$ COVID $\% 2$ D19\%20pandemic.\&text=Stress $\% 20$ was $\% 20$ the $\% 20 \mathrm{~m}$ ost $\% 20$ common,as\%20common\%20as\%20insufficient $\% 20$ pay

Grossoehme, D., \& Lipstein, E. (2016). Analyzing longitudinal qualitative data: The application of trajectory and recurrent cross-sectional approaches. BMC Research Notes, 9(136), 136-136. https://doi.org/10.1186/s13104-016-1954-1

Hobson, A., \& Maxwell, B. (2016). Supporting and inhibiting the well-being of early career secondary school teachers: Extending self-determination theory. British Educational Research Journal, 43(1), 168-191. https://doi.org/10.1002/berj.3261

Jacobsson, C., Åkerlund, M., Graci, E., Cedstrand, E., \& Archer, T. (2016). Teacher team effectiveness and teacher's well-being. Clinical Experiential Psychology, 2(130). doi:10.4172/24712701.1000130

Jennings, P.A., Brown, J.L., Frank, J.L., Doyle, S., Oh, Y., Davis, R., . . Greenberg, M.T. (2017). Impacts of the CARE for teachers program on teachers' social and emotional competence and classroom interactions. Journal of Educational Psychology, 109(7), 1010-1028. https://doi.org/10.1037/edu0000187

Johnson, S., Cooper, C., Cartwright, S., Donald, I., Taylor, P., \& Millet, C. (2005). The experience of work-related stress across occupations. Journal of Managerial Psychology, 20(2), 178-187. https://doi.org/10.1108/02683940510579803

Kern, M.L., Waters, L., Adler, A., \& White, M. (2014). Assessing employee well-being in schools using a multifaceted approach: Associations with physical health, life satisfaction, and professional thriving. Psychology, 5(6), 500-513. doi: 10.4236/psych.2014.56060

Kraft, M.A., Simon, N., \& Lyon, M. (2020). Sustaining a sense of success: The importance of teacher working conditions during the COVID-19 pandemic. EdWorkingPaper, pp. 20-279. https://doi.org/10.26300/35nj-v890

Lincoln, Y.S., \& Guba, E.G. (1985). Naturalistic inquiry. Thousand Oaks, CA: SAGE Publications.

MacIntyre, P.D., Gregersen, T., \& Mercer, S. (2020). Language teachers' coping strategies during the Covid-19 conversion to online teaching: Correlations with stress, wellbeing and negative emotions. System, 94, 102352. https://doi.org/10.1016/j.system.2020.102352

Mansfield, C.F., Beltman, S., Price, A., \& McConney, A. (2012). "Don't sweat the small stuff:" Understanding teacher resilience at the chalkface. Teaching and Teacher Education, 28(3), 357367. https://doi.org/10.1016/j.tate.2011.11.001

Maslach, C., \& Leiter, M.P. (1999). Teacher burnout: A research agenda. In R. Vandenberghe \& A.M. Huberman (Eds.), Understanding and preventing teacher burnout: A sourcebook of international research and practice (pp. 295-303). Cambridge University Press.

https://doi.org/10.1017/CBO9780511527784.021 
Maslow, A.H. (1943). A theory of human motivation. Psychological Review, 50(4), 370-396. https://doi.org/10.1037/h0054346

McCallum, F., \& Price, D. (2010). Well teachers, well students. Journal of Student Wellbeing, 4(1), 1934. Retrieved from https://ojs.unisa.edu.au/index.php/JSW/article/view/599

McCallum, F., Price, D., Graham, A., \& Morrison, A. (2017). Teacher wellbeing: A review of the literature. Association of Independent Schools of NSW, The University of Adelaide, Australia, p.34. Retrieved from https://apo.org.au/node/201816

Owen, S. (2016). Professional learning communities: Building skills, reinvigorating the passion, and nurturing teacher wellbeing and "flourishing" within significantly innovative schooling contexts. Educational Review, pp. 1-17. https://doi.org/10.1080/00131911.2015.1119101

Player, D., Youngs, P., Perrone, F., \& Grogan, E. (2017). How principal leadership and person-job fit are associated with teacher mobility and attrition. Teaching \& Teacher Education, 67, 330-339. https://doi.10.1016/j.tate.2017.06.017

Ross, S.W., Romer, N., \& Horner, R.H. (2012). Teacher well-being and the implementation of schoolwide positive behavior interventions and supports. Journal of Positive Behavior Interventions, 14(2), 118-128. https://doi.org/10.1177/1098300711413820

Skaalvik, E.M., \& Skaalvik, S. (2009). Does school context matter? Relations with teacher burnout and job satisfaction. Teaching and Teacher Education, 25, 518-524. http://dx.doi.org/10.1016/j.tate.2008.12.006

The UN Refugee Agency. (n.d.). Refugee teacher management (Education Issue Brief \# 5). UNHCR The UN Refugee Agency, USA. Retrieved from https://www.unhcr.org/publications/education/560be1629/education-brief-5-refugee-teachermanagement.html

Ungar, M. (2012). Social ecologies and their contribution to resilience. In M. Ungar (Ed.), The social ecology of resilience: A handbook of theory and practice (pp. 13-32). New York: Springer.

Wang, H., \& Hall, N.C. (2019). When "I care" is not enough: An interactional analysis of teacher values, value congruence, and well-being. Teaching and Teacher Education, 86. https://doi.org/10.1016/j.tate.2019.102906

Wong, V., Ruble, L.A., Yu, Y., \& McGrew, J.H. (2017). Too Stressed to Teach? Teaching Quality, Student Engagement, and IEP Outcomes. Exceptional Children, 83(4), 412-427. https://doi.org/10.1177/0014402917690729

Yin, H., Huang, S., \& Lv, L. (2018). A Multilevel Analysis of Job Characteristics, Emotion Regulation, and Teacher Well-Being: A Job Demands-Resources Model. Frontiers in Psychology, 9, 2395. https://doi.org/10.3389/fpsyg.2018.02395 